\title{
Estrutura da Comunidade Arbórea de Trecho de Floresta Estacional Sempre-Verde e Similaridade Florística na Região Nordeste do Mato Grosso, Brasil
}

\author{
Sustanis Horn Kunz ${ }^{1}$, Julia Moreau², Cristiani Spadeto ${ }^{2}$, \\ Sebastião Venâncio Martins ${ }^{3}$, Daniel Stefanello ${ }^{4}$, \\ Natália Macedo Ivanauskas ${ }^{5}$
}

${ }^{1}$ Departamento de Ciências Florestais e da Madeira, Universidade Federal do Espírito Santo - UFES, Alegre/ES, Brasil ${ }^{2}$ Programa de Pós-graduação em Ciências Florestais, Universidade Federal do Espírito Santo - UFES, Alegre/ES, Brasil ${ }^{3}$ Departamento de Engenharia Florestal, Universidade Federal de Viçosa - UFV, Viçosa/MG, Brasil ${ }^{4}$ Escola Municipal, Prefeitura Municipal de Querência, Querência/MT, Brasil

${ }^{5}$ Divisão de Dasonomia, Instituto de Pesquisas Florestais do Estado de São Paulo, São Paulo/SP, Brasil

\begin{abstract}
RESUMO
Este trabalho apresenta a estrutura de trechos de Floresta Estacional Sempre-Verde do Rio das Pacas e avalia a similaridade florística de dez áreas localizadas nas Bacias Hidrográficas Pacuneiro e Pacas, Mato Grosso. Foram alocadas 14 parcelas $(25 \times 10 \mathrm{~m})$ em cada trecho (nascente, meio e foz), sendo amostrados todos os indivíduos com Circunferência à Altura do Peito $\geq 15 \mathrm{~cm}$ e realizada a análise dos parâmetros fitossociológicos, além da similaridade florística pelo Índice de Jaccard. A densidade total foi de 1.606 ind./ha. As famílias com maior riqueza foram Anonnaceae (9 espécies); Fabaceae (9); Melastomataceae (6) e Burseraceae (5). As espécies Jacaranda copaia (Aubl.) D. Don, Ocotea caudata (Nees) Mez, Ocotea guianensis Aubl. e Zigia cataractae (Kunth) L. Rico tiveram maior valor de importância. O Índice de Shannon $(3,67)$ e o índice de equabilidade $(0,86)$ mostraram-se semelhantes aos de outras florestas ribeirinhas. As áreas de nascente e meio apresentaram maior similaridade florística $(\mathrm{J}=0,71)$.
\end{abstract}

Palavras-chave: fitossociologia, Xingu, Floresta Amazônica.

\section{Structure of the Arboreal Community of an Evergreen Seasonal Forest Stand and Floristic Similarity in Northeastern Mato Grosso State, Brazil}

\begin{abstract}
This study presents the structure of forest stands of an Evergreen Seasonal Forest along the Pacas River and evaluates the floristic similarity of ten areas located in the Pacuneiro and Pacas river basins in Mato Grosso state, Brazil. Each section (source, middle, and mouth) was divided into 14 plots $(25 \times 10 \mathrm{~m})$. All individuals with diameter at breast height $(\mathrm{DBH}) \geq 15 \mathrm{~cm}$ were sampled. Phytosociological parameters and floristic similarity (by Jaccard index) were analyzed. Total density was 1,606 ind./ha. The most commonly found families in number of species were Anonnaceae (9), Fabaceae (9), Melastomataceae (6), and Burseraceae (5). The species Jacaranda copaia (Aubl.) D. Don, Ocotea caudata (Nees) Mez, Ocotea guianensis Aubl., and Zigia cataractae (Kunth) L. Rico presented the highest importance values. The Shannon (3.67) and equability (0.86) indexes found were similar to those of other riparian forests. The areas of the source and middle of the river showed the highest floristic similarity $(J=0.71)$.
\end{abstract}

Keywords: phytosociology, Xingu, Amazon Forest. 


\section{INTRODUÇÃO}

As formações florestais encontradas ao longo dos cursos d'água - denominadas de florestas ciliares, ribeirinhas (Budke et al., 2005), galerias (Ribeiro \& Walter, 2001) ou ripárias (Romagnolo \& Souza, 2000) - são caracterizadas pela alta heterogeneidade ambiental, devido a diversos fatores físicos e bióticos que atuam sobre estas, modificando as características do ambiente e regulando a distribuição e a organização da comunidade florestal (Rodrigues \& Shepherd, 2000). Por vezes, tais termos são usados igualmente, mesmo se tratando de regiões e formações florestais distintas, o que resulta em interpretações errôneas (Ribeiro \& Walter, 2001).

Dentro dessa situação, encontra-se um tipo peculiar de floresta na região do Alto Rio Xingu, borda sul-amazônica, na área de contato entre a Floresta Ombrófila, a Floresta Estacional e o Cerrado, denominada de Floresta Estacional Sempre-Verde (IBGE, 2012). Esta formação apresenta composição florística própria (Ivanauskas et al., 2008; Kunz et al., 2009), embora esteja inserida em uma região caracterizada como zona de tensão ecológica (Veloso et al., 1991; IBGE, 1993) ou ecorregião das florestas secas do Mato Grosso (Ferreira et al., 1999).

A origem desta floresta ainda é pouco conhecida, pois os estudos realizados na região são voltados especificamente para a composição florística e a estrutura da vegetação, sendo que estes ainda são escassos e restritos a áreas de terra firme. Estes estudos foram realizados na região nordeste do Estado de Mato Grosso, com a maioria na Bacia do Rio das Pacas, em Querência (Kunz et al., 2008; 2010a, b, 2012), e outros na Bacia do Rio Pacuneiro, em Gaúcha do Norte (Ivanauskas et al., 2004a, b). Esses autores estudaram a composição florística e a estrutura da floresta ciliar do Rio Pacuneiro, caracterizando-a como Floresta Estacional Perenifólia ribeirinha, da qual não se conhecem seus limites geográficos e suas características físico-biológicas que favorecem seu estabelecimento.

No entanto, de acordo com o novo Manual Técnico da Vegetação Brasileira (IBGE, 2012), a região do Alto Rio Xingu é caracterizada como Floresta Estacional Sempre-Verde Submontana, mas ainda existem grandes lacunas no que diz respeito ao conhecimento da estrutura e da composição florística de tais florestas, que ocorrem ao longo dos rios nesta região. Observe-se que os rios são extremamente necessários para auxiliar na caracterização fitofisionômica da região, definindo claramente sua abrangência e as características particulares que a tornam distinta das demais formações de contato.

Diante da dificuldade de um mapeamento detalhado, estudos relacionados à estrutura da vegetação e florística podem facilitar o entendimento da fitogeografia regional, pois permitem avaliar as semelhanças e as diferenças na composição de uma determinada comunidade vegetal em relação à composição de outras regiões (Meira-Neto \& Martins, 2002), além de serem úteis na avaliação da heterogeneidade ambiental dos ecossistemas naturais. Estudos dessa natureza têm também grande aplicação na definição de ecossistemas de referência em projetos de restauração florestal.

Neste contexto, o objetivo deste estudo é apresentar a estrutura de trecho de Floresta Estacional Sempre-Verde do Rio das Pacas, bem como avaliar a similaridade florística entre áreas ribeirinhas de duas bacias hidrográficas (Pacuneiro e Pacas) da região do Xingu. Dessa forma, este estudo pode servir de base para auxiliar na determinação da abrangência geográfica desta formação florestal na região nordeste do Estado do Mato Grosso.

\section{MATERIAL E MÉTODOS}

\section{1. Área de estudo}

O Rio das Pacas está localizado na mesorregião nordeste mato-grossense e abrange a porção norte do município de Querência, a aproximadamente $700 \mathrm{~km}$ da capital Cuiabá (Figura 1). O Rio das Pacas deságua no Rio Suiá-Miçu, o qual, por sua vez, compreende uma das principais bacias formadoras do Rio Xingu. O clima da região é classificado como Tropical de Savana (Aw), segundo classificação Köppen (1948), havendo duas estações bem definidas: a chuvosa, que ocorre no período de outubro a abril, e a seca, que corresponde aos meses de maio a setembro (SEPLAN/MT, 1999).

$\mathrm{Na}$ Bacia do Rio das Pacas, predomina a Floresta Estacional Sempre-Verde nas áreas de interflúvio 


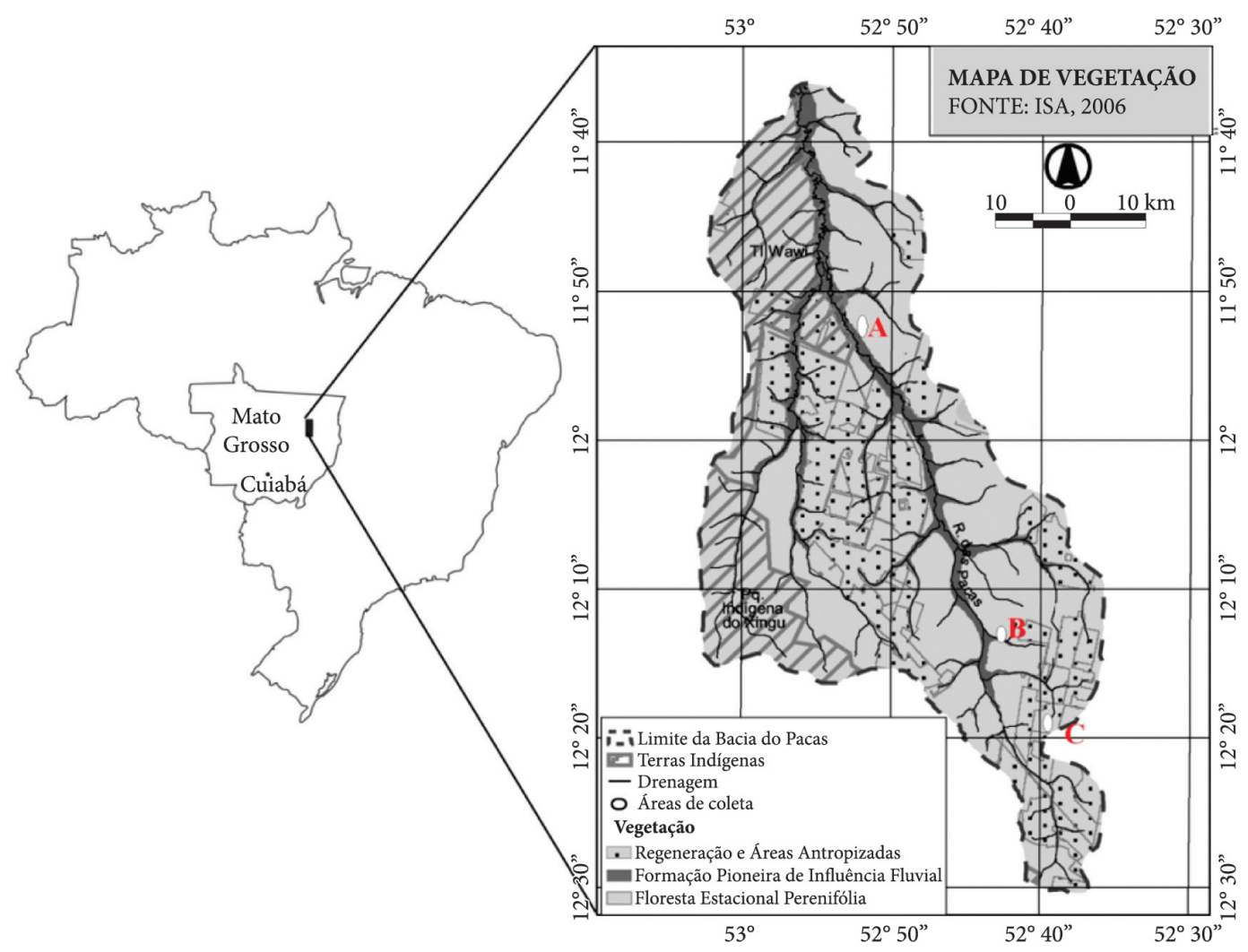

Figura 1. Localização da Bacia do Rio das Pacas, com destaque para as áreas de estudo (A) Foz, (B) Meio e (C) Nascente, município de Querência-MT.

Figure 1. Location of the river basin of Pacas, highlighting areas of study (A) Foz, (B) Mean and (C) Rising, municipality of Querencia - MT.

e ribeirinhas (IBGE, 2012). Nas áreas inundáveis temporariamente, nas quais foi realizado o presente estudo, a vegetação é denominada de Floresta Estacional Sempre-Verde Aluvial, de acordo com a classificação proposta pelo IBGE (2012). O relevo das áreas amostradas é basicamente plano, com altitude em torno de $350 \mathrm{~m}$, e os solos são classificados como Neossolos (A. N. Rossete - comunicação pessoal).

Foram determinadas três áreas de estudo, denominadas de foz ( $11^{\circ} 51^{\prime} 37^{\prime \prime} \mathrm{S}$ e $\left.52^{\circ} 52^{\prime} 49^{\prime \prime} \mathrm{W}\right)$; meio (12 $11^{\prime} 51,9^{\prime \prime S}$ e $\left.52^{\circ} 39^{\prime} 40,2^{\prime \prime} \mathrm{W}\right)$ e nascente do rio $\left(12^{\circ} 27^{\prime} 59,6^{\prime \prime S}\right.$ e $52^{\circ} 35^{\prime} 42,7^{\prime \prime} \mathrm{W}$ ) (Figura 1). A escolha dos trechos foi baseada na ausência de sinais de perturbação, como o extrativismo, e na homogeneidade das características físicas do ambiente, como relevo, grau de inundação e proximidade do curso d'água.

\subsection{Amostragem da vegetação}

O método de amostragem utilizado foi o de parcelas (Durigan et al., 2003). Foram instaladas em cada trecho (nascente, meio e foz) 14 parcelas de $25 \mathrm{~m} \times 10 \mathrm{~m}\left(250 \mathrm{~m}^{2}\right)$, totalizando área amostral de $10.500 \mathrm{~m}^{2}$. As parcelas foram alocadas paralelamente ao curso d'água e com espaçamento de $10 \mathrm{~m}$ entre si. Nestas parcelas, foram amostrados todos os indivíduos com circunferência à altura do peito (CAP) $\geq 15 \mathrm{~cm}$. Para os indivíduos que perfilhavam, foi adotado o seguinte critério: o indivíduo foi incluído quando pelo menos uma das ramificações obedecia ao critério de inclusão (CAP $\geq 15 \mathrm{~cm}$ ), sendo então anotadas todas as ramificações para o cálculo da área basal.

Foram coletadas as amostras botânicas de cada espécie para a identificação, realizada por meio de 
consulta à bibliografia adequada e comparação com exsicatas existentes no herbário NX (Coleção James Alexander Ratter, UNEMAT - Campus Universitário de Nova Xavantina, Mato Grosso). A identificação seguiu o sistema de classificação da APG III (2009) e os nomes científicos foram conferidos mediante consulta à página do Missouri Botanical Garden (MOBOT, 2008). Após a identificação, o material foi incorporado ao herbário da Universidade do Estado de Mato Grosso - Campus de Nova Xavantina (Herbário NX).

\subsection{Análise dos dados}

A análise da estrutura horizontal da comunidade arbórea foi realizada para o conjunto das três áreas amostradas (nascente, meio e foz). Os parâmetros fitossociológicos considerados - Densidade, Frequência, Dominância e Valor de Importância foram aplicados de acordo com Mueller-Dombois \& Ellenberg (1974) e Durigan et al. (2003), e foram estimados o Índice de Diversidade de Shannon $\left(H^{\prime}\right)$ e a equabilidade (J') (Pielou, 1975). Quanto à diversidade florística, foi aplicado o teste $t$ de Hutcheson (1970), para comprovar a semelhança ou não da diversidade entre os trechos (nascente, meio e foz), pelos valores gerados do Índice de Shannon $\left(\mathrm{H}^{\prime}\right)$. Esta análise foi realizada pelo programa PAST versão 2.16 (Hammer et al., 2001).

A composição florística da área em estudo foi comparada com os levantamentos florístico e fitossociológico realizados em sete áreas distintas do Estado do Mato Grosso, a partir das listagens de espécies arbustivo-arbóreas amostradas nos trabalhos descritos na Tabela 1. Posteriormente, uma matriz binária de presença e ausência foi elaborada, considerando-se apenas as fanerógamas com binômio completo, sendo excluídos os indivíduos classificados apenas em nível de família e gênero. Segundo Salis et al. (1995), a classificação apenas nestes níveis dificulta comparar estas taxas com aquelas identificadas em nível de espécie, tornando os resultados da análise duvidosos ou tendenciosos.

A similaridade florística foi calculada por meio do Índice de Jaccard, como proposto por Silva \& Shepherd (1986), Torres et al. (1997), Durigan et al. (2003), Martins et al. (2004) e Rossato et al. (2008). O Índice de Jaccard considera o número de espécies comuns entre duas áreas (a) e o número de espécies exclusivas de cada área (b, c) (Mueller-Dombois \& Ellenberg, 1974):

$J=100 a /(a+b+c)$

Com base neste índice, elaborou-se um dendrograma baseado na média de grupo (UPGMA), no qual o agrupamento é feito a partir da média aritmética dos elementos, em que os valores das ordenadas expressam as relações de similaridade entre os objetos indicados nas abscissas (Sneath \& Sokal, 1973). As análises foram realizadas por meio dos programas do pacote FITOPAC 2 (Shepherd, 2010).

\section{RESULTADOS E DISCUSSÃO}

A flora inventariada em 1,05 ha de vegetação no Rio das Pacas resultou em 67 espécies, distribuídas em 31 famílias botânicas. As maiores riqueza e abundância foram registradas no trecho do meio do rio (Tabela 2).

Em estudo realizado em floresta estacional sempre-verde aluvial em Gaúcha do Norte-MT, foi encontrada riqueza inferior (57); no entanto, foi utilizado como critério de inclusão indivíduos com $\mathrm{DAP} \geq 10 \mathrm{~cm}$. O mesmo foi observado para a área de interflúvio da margem direita do Rio Pacuneiro (58); já na área de interflúvio da margem esquerda do mesmo rio, o número de espécies (65) se assemelhou ao encontrado neste estudo (Ivanauskas et al., 2004b). Note-se que nas áreas de interflúvio do Rio das Pacas, a riqueza variou entre 49 e 53 (Kunz et al., 2008, 2010b), utilizando-se o mesmo critério de inclusão.

No trecho do meio do Rio das Pacas a diversidade florística foi maior, mas não houve diferença significativa entre os locais, pelo teste $t$ de Hutcheson (nascente e meio, $\mathrm{t}=-4,22, P=2,56$; nascente e foz, $\mathrm{t}=1,59, P=0,11$; foz e meio, $\mathrm{t}=-6,06, P=1,85)$.

O Índice de Diversidade de Shannon $(3,67)$ está próximo aos valores encontrados em outras áreas ciliares. Valores mais baixos foram encontrados por Almeida et al. (2004), estudando uma floresta de várzea localizada no baixo Rio Xingu (2,85 nats/ ind.). Já Oliveira-Filho (1989) obteve o valor de diversidade de 4,30 nats/ind., em uma floresta de 


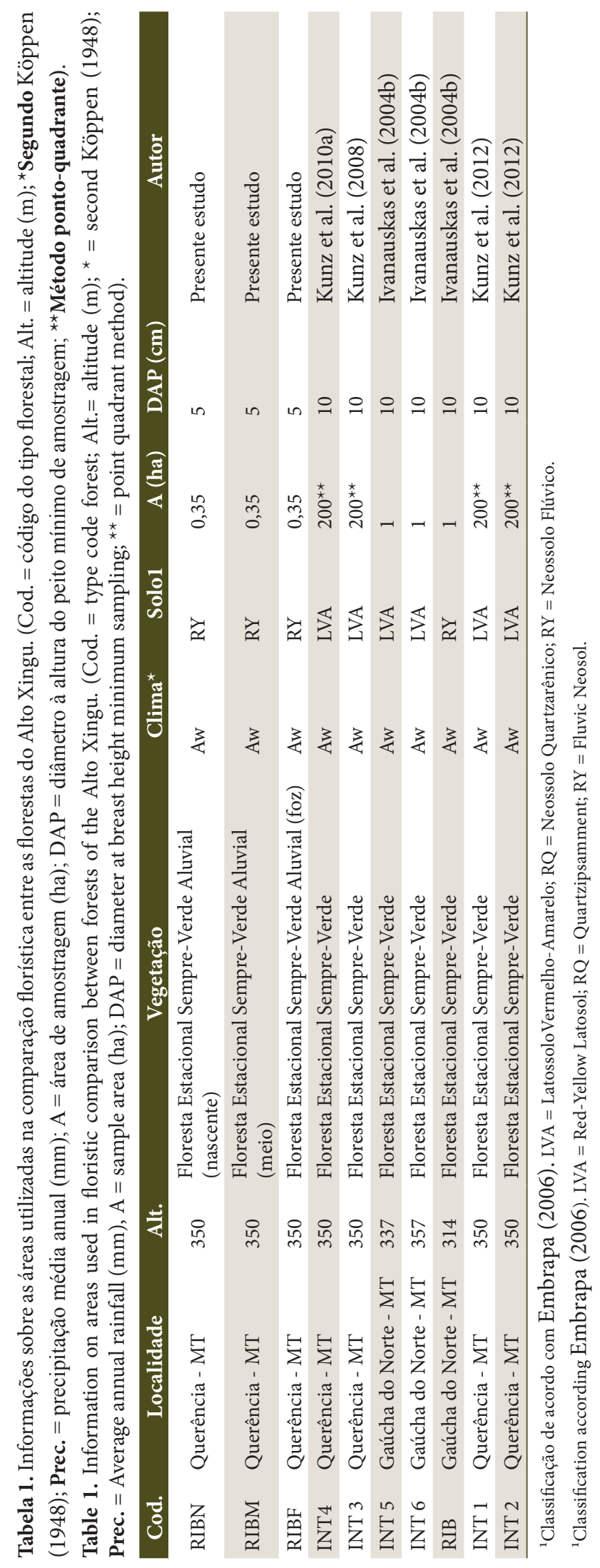


Tabela 2. Parâmetros comparativos de estrutura e diversidade da vegetação ribeirinha do Rio Pacas, Querência-MT.

Table 2. Comparative parameters of structure and diversity of riparian vegetation river Pacas, Querência - MT.

\begin{tabular}{ccccccc} 
Locais & $\begin{array}{c}\text { Área } \\
\text { Basal }\left(\mathbf{m}^{\mathbf{2}} \mathbf{h a} \mathbf{h}\right)\end{array}$ & Espécies (n) & $\begin{array}{c}\text { Indivíduos } \\
(\mathbf{n})\end{array}$ & Famílias (n) & H' & J' \\
\hline Nascente & 22,02 & 47 & 572 & 25 & 3,29 & 0,85 \\
Meio & 26,27 & 53 & 602 & 28 & 3,52 & 0,88 \\
Foz & 22,48 & 41 & 514 & 22 & 3,20 & 0,85 \\
Total & 22,94 & 67 & 1687 & 31 & 3,67 & 0,86 \\
\hline
\end{tabular}

galeria, e Pinto \& Oliveira-Filho (1999), estudando uma floresta de vale, obtiveram valor de 4,34 nats/ ind., ambos no Estado do Mato Grosso. Resultados semelhantes ao do presente estudo foram obtidos nos trabalhos realizados por Bertani et al. (2001), em Floresta Estacional Semidecidual ribeirinha, e por Pereira et al. (2012), em mata ciliar de encosta no alto Rio Grande, Minas Gerais, cujos valores estão entre 3,53 e 3,70 .

Mesmo apresentando valores intermediários, o Índice de Shannon encontrado para o presente estudo pode ser considerado alto quando comparado com o trabalho desenvolvido na região do Alto Rio Xingu, por Ivanauskas et al. (2004b), pois esses autores encontraram uma diversidade florística de 3,07 nats/ind. em áreas ribeirinhas de floresta estacional sempre-verde na Bacia do Pacuneiro, região nordeste do Estado do Mato Grosso. Adicionalmente, o valor de equabilidade $(0,86)$ encontrado demonstra que não existe alta concentração de abundância por poucas espécies na comunidade, havendo baixa dominância ecológica (Kunz et al., 2008), além de se assemelhar aos resultados dos estudos mencionados acima, com exceção de Ivanauskas et al. (2004b), que observaram valor inferior de equabilidade $(0,76)$.

Os gêneros com elevada riqueza florística foram Miconia (5 espécies); Xylopia (4); Ocotea, Protium e Myrcia (3), os quais representam 26,9\% das espécies registradas neste estudo. As famílias de maior riqueza foram Anonnaceae (9 espécies); Fabaceae (9); Melastomataceae (6); Burseraceae (5). Estas representaram 43,3\% ( $\mathrm{N}=29)$ do total de espécies amostradas na comunidade. Esta alta representatividade em poucas famílias botânicas para a Região Amazônica confirma o que já havia sido observado por Oliveira et al. (2003), Oliveira \& Amaral (2004), Espírito-Santo et al. (2005), Oliveira \& Amaral (2005), Silva et al. (2008) e Kunz et al.
(2008, 2010b) os quais relatam que a alta diversidade florística concentra-se em poucas famílias botânicas.

As espécies Jacaranda copaia, Ocotea caudata, Ocotea guianensis e Zigia cataractae se destacaram em Valor de Importância (VI), na comunidade arbórea ribeirinha do Rio das Pacas (Tabela 3), representando $23,33 \%$ do VI.

O destaque para Jacaranda copaia se deve principalmente pelo valor de dominância, pois os valores de densidade e frequência foram próximos àqueles encontrados para O. caudata, O. guianensis e Z. cataractae. Estas, por sua vez, são bastante numerosas e parecem apresentar ampla distribuição na área de estudo. Miconia pyrifolia, Sacoglottis guianensis e Miconia punctata, apesar de estarem representadas por menor número de indivíduos, também apresentaram elevados VIs, devido ao elevado diâmetro.

Dentre as espécies com elevados VIs, Jacaranda copaia e Ocotea guianensis também foram amostradas em área de interflúvio do trabalho realizado por Ivanauskas et al. (2004b), sendo que Zigia cataractae esteve presente na faixa ribeirinha desse mesmo levantamento florístico, realizado nas margens do Rio Pacuneiro em Gaúcha do Norte-MT. Kunz et al. (2010a) registraram as mesmas espécies em estudo efetuado na Bacia do Rio das Pacas, demonstrando que estas são espécies comuns nas áreas de interflúvio e ribeirinha na região do alto Rio Xingu, apesar de não representarem a mesma importância nas diferentes regiões.

A densidade total e a área basal estimada foram de 1.606 indivíduos/ha e $22,94 \mathrm{~m}^{2} / \mathrm{ha}$, respectivamente. Ivanauskas et al. (2004b), estudando uma floresta com influência fluvial sazonal (ribeirinha), localizada no Rio Pacuneiro, em Gaúcha do Norte-MT, encontraram uma comunidade arbóreo-arbustiva $(\mathrm{DAP} \geq 10 \mathrm{~cm})$ com densidade de 515 indivíduos/ha 
Tabela 3. Parâmetros fitossociológicos das espécies arbóreas amostradas na comunidade ribeirinha do Rio das Pacas, Querência-MT. NI - Número de indivíduos; DR - Densidade relativa (\%); DoR - Dominância relativa (\%); FR - Frequência relativa (\%); VI - Valor de importância (\%).

Table 3. Phytosociological parameters of arborous species sampled in the river community of river Querencia-MT. NI - Number of individuals, DR - Relative density (\%), DoR - Relative dominance (\%), FR - Relative frequency (\%), VI - Importance value.

\begin{tabular}{|c|c|c|c|c|c|c|}
\hline ESPÉCIES & NI & DR & FR & DoR & VI & VI (\%) \\
\hline Jacaranda copaia (Aubl.) D. Don & 108 & 6,40 & 3,37 & 11,82 & 21,59 & 7,20 \\
\hline Ocotea caudata (Nees) Mez & 114 & 6,76 & 4,92 & 6,15 & 17,83 & 5,94 \\
\hline Ocotea guianensis Aubl. & 122 & 7,23 & 3,50 & 5,80 & 16,53 & 5,51 \\
\hline Zigia cataractae (Kunth) L. Rico & 77 & 4,56 & 3,24 & 6,28 & 14,08 & 4,69 \\
\hline Miconia pyrifolia Naudin & 68 & 4,03 & 4,15 & 3,97 & 12,15 & 4,05 \\
\hline Sacoglottis guianensis Benth. & 62 & 3,68 & 2,59 & 5,13 & 11,40 & 3,80 \\
\hline Miconia punctata (Desr.) D. Don ex DC & 57 & 3,38 & 3,89 & 3,78 & 11,05 & 3,68 \\
\hline Ocotea leucoxylon (Sw.) Laness. & 50 & 2,96 & 2,72 & 5,31 & 11,00 & 3,67 \\
\hline Myrcia sp. & 85 & 5,04 & 2,85 & 1,76 & 9,65 & 3,22 \\
\hline Protium pilosissimum (Engl.) D.C. Daly & 71 & 4,21 & 3,63 & 1,69 & 9,53 & 3,18 \\
\hline Sloanea eichleri K. Schum. & 59 & 3,50 & 3,63 & 2,35 & 9,47 & 3,16 \\
\hline Hirtella racemosa Lam. & 35 & 2,07 & 2,46 & 3,94 & 8,48 & 2,83 \\
\hline Trattinnickia glaziovii Swart & 45 & 2,67 & 2,98 & 1,38 & 7,03 & 2,34 \\
\hline Chaetocarpus echinocarpus (Baill.) Ducke & 49 & 2,90 & 2,07 & 1,94 & 6,92 & 2,31 \\
\hline Miconia acutifolia Ule & 24 & 1,42 & 1,94 & 2,94 & 6,30 & 2,10 \\
\hline Inga thibaudiana D.C. & 36 & 2,13 & 2,33 & 1,76 & 6,22 & 2,07 \\
\hline Inga heterophylla Willd. & 36 & 2,13 & 2,33 & 1,65 & 6,12 & 2,04 \\
\hline Connarus perrottetii (DC.) Planch. & 26 & 1,54 & 2,59 & 1,65 & 5,79 & 1,93 \\
\hline Miconia dispar Benth. & 39 & 2,31 & 2,72 & 0,72 & 5,76 & 1,92 \\
\hline Ouratea discophora Ducke & 41 & 2,43 & 1,94 & 1,15 & 5,53 & 1,84 \\
\hline Acosmium dasycarpum (Vogel) Yakovlev & 19 & 1,13 & 1,94 & 2,44 & 5,51 & 1,84 \\
\hline Trichilia micrantha Benth. & 34 & 2,02 & 2,33 & 0,80 & 5,14 & 1,71 \\
\hline Guatteria schomburgkiana Mart. & 25 & 1,48 & 1,68 & 0,92 & 4,09 & 1,36 \\
\hline Vochysia vismiifolia Sprunce ex Warm. & 10 & 0,59 & 1,17 & 2,30 & 4,06 & 1,35 \\
\hline Schefflera morototoni (Aubl.) Maguire, Steyerm. \& Frodin & 15 & 0,89 & 1,55 & 1,61 & 4,05 & 1,35 \\
\hline Licania blackii Prance & 23 & 1,36 & 1,94 & 0,72 & 4,02 & 1,34 \\
\hline Maprounea guianensis Aubl. & 25 & 1,48 & 1,81 & 0,66 & 3,96 & 1,32 \\
\hline Protium guianense (Aubl.) Marchand & 28 & 1,66 & 1,68 & 0,61 & 3,96 & 1,32 \\
\hline Myrcia amazonica DC. & 25 & 1,48 & 1,81 & 0,61 & 3,90 & 1,30 \\
\hline Tapirira guianensis Aubl. & 19 & 1,13 & 1,30 & 1,28 & 3,71 & 1,24 \\
\hline Xylopia amazonica R.E.Fr. & 16 & 0,95 & 1,55 & 1,17 & 3,67 & 1,22 \\
\hline Enterolobium schomburgkii (Benth.) Benth. & 1 & 0,06 & 0,13 & 3,44 & 3,63 & 1,21 \\
\hline Protium spruceanum (Benth.) Engl. & 24 & 1,42 & 1,30 & 0,6 & 3,32 & 1,11 \\
\hline Guatteria blepharophylla Mart. & 18 & 1,07 & 1,42 & 0,41 & 2,90 & 0,97 \\
\hline Cecropia glaziovii Snethl. & 17 & 1,01 & 1,04 & 0,85 & 2,89 & 0,96 \\
\hline Euterpe edulis Mart. & 11 & 0,65 & 1,17 & 0,91 & 2,73 & 0,91 \\
\hline Abuta grandifolia (Mart.) Sandwith & 13 & 0,77 & 1,55 & 0,37 & 2,70 & 0,90 \\
\hline Amaioua guianensis Aubl. & 13 & 0,77 & 1,30 & 0,38 & 2,45 & 0,82 \\
\hline Virola sebifera Aubl. & 17 & 1,01 & 0,78 & 0,43 & 2,21 & 0,74 \\
\hline Sclerolobium aureum (Tul.) Baill. & 5 & 0,30 & 0,39 & 1,31 & 2,00 & 0,67 \\
\hline Ephedranthus amazonicus R.E. Fr. & 11 & 0,65 & 1,04 & 0,17 & 1,85 & 0,62 \\
\hline Abarema piresii Barneby \& J.W. Grimes & 7 & 0,41 & 0,65 & 0,72 & 1,79 & 0,60 \\
\hline Xylopia nitida Dunal & 7 & 0,41 & 0,78 & 0,27 & 1,47 & 0,49 \\
\hline Xylopia crinita R.E. Fr. & 7 & 0,41 & 0,65 & 0,36 & 1,42 & 0,47 \\
\hline Brosimum lactescens (S. Moore) C.C. Berg & 4 & 0,24 & 0,39 & 0,74 & 1,37 & 0,46 \\
\hline
\end{tabular}


Tabela 3. Continua...

Table 3. Continued...

\begin{tabular}{|c|c|c|c|c|c|c|}
\hline ESPÉCIES & NI & DR & FR & DoR & VI & VI (\%) \\
\hline Pouteria ramiflora (Mart.) Radlk. & 4 & 0,24 & 0,52 & 0,58 & 1,34 & 0,45 \\
\hline Quiina amazonica A.C. Sm. & 9 & 0,53 & 0,65 & 0,12 & 1,30 & 0,43 \\
\hline Xylopia sericea A. St.-Hil & 5 & 0,30 & 0,65 & 0,30 & 1,25 & 0,42 \\
\hline Micropholis egensis (A. DC.) Pierre & 5 & 0,30 & 0,65 & 0,29 & 1,24 & 0,41 \\
\hline Matayba guianensis Aubl. & 6 & 0,36 & 0,52 & 0,36 & 1,23 & 0,41 \\
\hline Matayba arborescens (Aubl.) Radlk. & 8 & 0,47 & 0,65 & 0,11 & 1,23 & 0,41 \\
\hline Miconia gratissima Benth. ex Triana & 7 & 0,41 & 0,65 & 0,14 & 1,20 & 0,40 \\
\hline Mouriri apiranga Spruce ex Triana & 5 & 0,30 & 0,65 & 0,25 & 1,19 & 0,40 \\
\hline Diplotropis purpurea (Rich.) Amshoff & 4 & 0,24 & 0,39 & 0,39 & 1,02 & 0,34 \\
\hline Cheiloclinium cognatum (Miers) A.C. Sm. & 6 & 0,36 & 0,52 & 0,06 & 0,94 & 0,31 \\
\hline Pseudolmedia macrophylla Trécul & 4 & 0,24 & 0,39 & 0,24 & 0,86 & 0,29 \\
\hline Handroanthus impetiginosus (Mart. ex DC.) Mattos & 4 & 0,24 & 0,52 & 0,09 & 0,84 & 0,28 \\
\hline Annona amazonica R.E. Fr. & 6 & 0,36 & 0,39 & 0,09 & 0,84 & 0,28 \\
\hline Trattinnickia burseralifolia Mart. & 1 & 0,06 & 0,13 & 0,53 & 0,72 & 0,24 \\
\hline Duguetia marcgraviana Mart. & 3 & 0,18 & 0,26 & 0,17 & 0,60 & 0,20 \\
\hline Mollia lepidota Spruce ex Benth. & 2 & 0,12 & 0,13 & 0,34 & 0,59 & 0,20 \\
\hline Pouteria torta (Mart.) Radlk. & 1 & 0,06 & 0,13 & 0,32 & 0,51 & 0,17 \\
\hline Bauhinia sp. & 2 & 0,12 & 0,26 & 0,02 & 0,40 & 0,13 \\
\hline Aspidosperma discolor A. DC. & 1 & 0,06 & 0,13 & 0,17 & 0,36 & 0,12 \\
\hline Myrcia multiflora (Lam.) DC. & 1 & 0,06 & 0,13 & 0,10 & 0,29 & 0,10 \\
\hline Siparuna poeppigii (Tul.) A. DC. & 2 & 0,12 & 0,13 & 0,03 & 0,27 & 0,09 \\
\hline Pera coccinea (Benth.) Müll. Arg. & 1 & 0,06 & 0,13 & 0,02 & 0,21 & 0,07 \\
\hline Hirtella gracilipes (Hook. f.) Prance & 1 & 0,06 & 0,13 & 0,01 & 0,20 & 0,07 \\
\hline Eriotheca candolleana (K. Schum.) A. Robyns & 1 & 0,06 & 0,13 & 0,01 & 0,20 & 0,07 \\
\hline Total & 1687 & 100 & 100 & 100 & 300 & 100 \\
\hline
\end{tabular}

e área basal de 23,95 m²/ha. Já Sampaio et al. (1997), estudando a diversidade e a distribuição de espécies arbóreas (DAP $\geq 5 \mathrm{~cm}$ ) em duas matas de galeria na Microbacia do Riacho Fundo-DF, amostraram 1.333 indivíduos/ha e área basal de $34,4 \mathrm{~m}^{2} / \mathrm{ha}$ para trechos não inundáveis e 2.094 indivíduos/ha e área basal $33,3 \mathrm{~m}^{2} /$ ha para áreas inundáveis. Por outro lado, Battilani et al. (2005) amostraram indivíduos arbóreo-arbustivos com DAP $\geq 3,18 \mathrm{~cm}$ e encontraram valores bem menores em trecho de mata ciliar do Rio da Prata, Jardim-MS, onde foram registrados 661 indivíduos com área basal de 19,19 $\mathrm{m}^{2}$ em uma área de 0,9 ha. Estes valores são muito dinâmicos, mostrando que o tipo de formação florestal e as condições físicas de cada ambiente, juntamente com o histórico de perturbações naturais e antrópicas, podem estar contribuindo para a densidade e a área basal das espécies.

O dendrograma de similaridade florística (Figura 2) indica a formação de dois grandes grupos. O grupo I é formado pelas áreas da Bacia do Rio das
Pacas (INT1, INT2, INT3, INT4, RIBF, RIBN, RIBM) e o grupo II, pelas áreas da Bacia do Rio Pacuneiro, em Gaúcha do Norte, Mato Grosso (INT5, INT6 e RIB). Apenas três espécies (2,08\% do total de espécies) Amaioua guianensis, Chaetocarpus echinocarpus e Xylopia amazonica - foram comuns a todas as áreas, o que demonstra baixa similaridade florística entre as áreas de floresta estacional sempre-verde. Apesar de as áreas estarem sob a mesma condição climática (Aw), essa divisão pode ser explicada pela disposição geográfica das bacias hidrográficas, que estão distantes entre si, ou ainda pela fertilidade do solo, cujo parâmetro ainda é pouco conhecido na região do alto Rio Xingu.

Kunz et al. (2009) relatam que mesmo com predomínio de um relevo suave na Floresta Estacional Sempre-Verde, as áreas de Gaúcha do Norte e Querência-MT estão localizadas em altitudes diferentes (314-357 m e 245-280 m, respectivamente). Resultado semelhante foi encontrado por Moreno et al. (2003), os quais observaram diferenças 


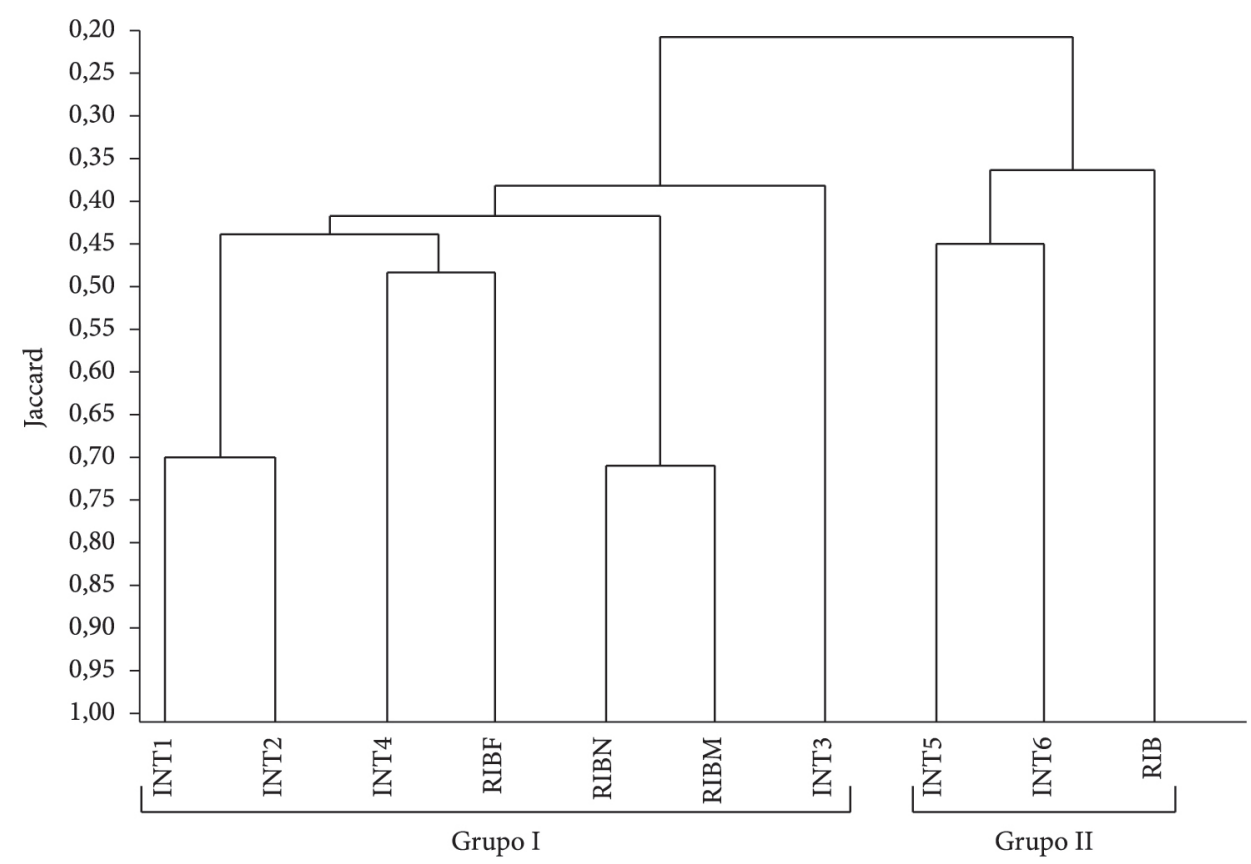

Figura 2. Dendrograma de análise de agrupamento (UPGMA), utilizando-se o Índice de Similaridade de Jaccard, para as áreas de floresta do Alto Xingu. Correlação cofenética: 0,92.

Figure 2. Dendrogram of cluster analysis (UPGMA) using the Jaccard similarity index for the forest areas of the Alto Xingu. Cophenetic correlation: 0.92.

na composição florística do estrato arbóreo ao avaliar distintas zonas altitudinais (50 m.s.m.-200 m.s.m.), evidenciando a possibilidade de variações na flora arbórea em decorrência dos níveis altitudinais em que as áreas se encontram. Gonçalves et al. (2011), estudando a distribuição do componente arbóreo de um trecho de mata ciliar, observaram que o mesmo também sofria influência ao longo do gradiente altitudinal, que variou de $706 \mathrm{~m}$ a $735 \mathrm{~m}$.

Além disso, ambas as áreas pertencem à Bacia Hidrográfica do Xingu, uma bacia muito extensa, em que Kunz et al. (2009) sugerem a possibilidade da existência de um mosaico espacial de condições físicas que se expressam de forma diferente, o que poderia explicar as diferenças florísticas mesmo entre áreas relativamente próximas. Alguns autores relatam que a baixa similaridade florística, mesmo de locais próximos, é reflexo da heterogeneidade espacial dos ambientes ribeirinhos. Esta heterogeneidade, por sua vez, pode estar condicionada à variação da elevação do nível de água e do grau de umidade do solo (Rodrigues \& Shepherd, 2000; Bertani et al., 2001; Güntzel et al., 2011); características edáficas, como fertilidade do solo e acidez (Teixeira \& Assis, 2009;
Gonçalves et al., 2011); gradiente altitudinal e estágio sucessional (Umetsu et al., 2011; Pereira et al., 2012), e conectividade com a vegetação circunvizinha (Marchi \& Jarenkow, 2008).

O grupo I apresentou subdivisões contendo áreas ribeirinhas e de terra firme, com destaque para o distanciamento das áreas deste estudo, sendo que o trecho de nascente (RIBN) e o trecho do meio do Rio das Pacas (RIBM) apresentaram maior similaridade $(\mathrm{J}=0,71)$. Apesar de estas duas áreas apresentarem as mesmas condições climáticas e edáficas em relação à foz do rio, esta manteve maior similaridade florística com um trecho de floresta de terra firme (INT4). Possivelmente, esta semelhança pode ser pelo fato de que o trecho de foz amostrado situa-se próximo ao trecho de floresta de terra firme e mais distante das demais áreas ribeirinhas do Rio das Pacas.

\section{CONCLUSÃO}

A estrutura da vegetação arbórea ribeirinha do Rio das Pacas é formada por espécies que não se destacam no ambiente em valor de importância. Jacaranda copaia, Ocotea caudata e Ocotea guianensis 
apresentaram maior número de indivíduos, mas os valores de densidade, frequência e dominância sugerem que o ambiente físico pode estar limitando o desenvolvimento dos indivíduos, tornando a estrutura da comunidade mais homogênea.

A distinção florística entre as bacias hidrográficas confirma a heterogeneidade da Floresta Estacional Sempre-Verde. Mesmo considerando-se um continuum florestal desta fitofisionomia, conclui-se que as áreas ribeirinhas podem mostrar uma fraca relação florística entre diferentes cursos hídricos, cuja distinção provavelmente estará associada às características físicas de cada corpo d'água. Por se tratar de áreas ribeirinhas, é necessário que outros estudos sejam realizados considerando-se a caracterização física do ambiente, para que haja melhor elucidação destas variações florísticas encontradas.

A conservação das florestas ciliares do presente estudo torna-se de fundamental importância, dado o pouco conhecimento acumulado dessas áreas. A partir do conhecimento dos aspectos essenciais à sustentabilidade das florestas ciliares, como composição, riqueza de espécies e organização estrutural, com os resultados obtidos neste estudo, é possível discutir medidas que objetivem desencadear a importância de se conservar a cobertura vegetal desses fragmentos.

\section{AGRADECIMENTOS}

À CAPES, pela concessão da bolsa de mestrado ao quinto autor.

\section{STATUS DA SUBMISSÃO}

Recebido: 07 fev., 2013

Aceito: 14 ago., 2014

Publicado: 21 nov., 2014

\section{AUTOR(ES) PARA CORRESPONDÊNCIA}

\section{Cristiani Spadeto}

Programa de Pós-graduação em Ciências

Florestais, Universidade Federal do Espírito Santo - UFES, CEP 29500-000, Alegre, ES, Brasil

e-mail: sustanis.kunz@ufes.br

\section{REFERÊNCIAS}

Almeida SS, Amaral DD, Silva ASL. Análise florística e estrutura de florestas de Várzea no estuário Amazônico. Acta Amazonica 2004; 34(4): 513-524. http://dx.doi. org/10.1590/S0044-59672004000400005.

Angiosperm Phylogeny Group - APG III. An update of the Angiosperm Phylogeny Group classification for the orders and families of flowering plants: APG III. Botanical Journal of the Linnean Society 2009; 161(2): 105-121. http://dx.doi.org/10.1111/j.10958339.2009.00996.x.

Battilani JL, Sremin-Dias E, Souza ALT. Fitossociologia de um trecho da mata ciliar do rio da Prata, Jardim, MS, Brasil. Acta Botanica Brasilica 2005; 19(3): 597-608. http://dx.doi.org/10.1590/S0102-33062005000300021.

Bertani DF, Rodrigues RR, Batista JLF, Shepherd GJ. Análise temporal da heterogeneidade florística e estrutural em uma floresta ribeirinha. Revista Brasileira de Botânica 2001; 24(1): 11-23.

Budke JC, Athayde EA, Giehl ELH, Záchia RA, Eisinger SM. Composição florística e estratégias de dispersão de espécies lenhosas em uma floresta ribeirinha, arroio Passo das Tropas, Santa Maria, RS, Brasil. Iheringia. Série Botânica 2005; 60(1): 17-24.

Durigan G, Siqueira MF, Franco GADC, Bridgewater S, Ratter JA. The vegetation of priority areas for cerrado conservation in São Paulo State, Brazil. Edinburgh Journal of Botany 2003; 60(02): 217-241. http://dx.doi. org/10.1017/S0960428603000155.

Empresa Brasileira de Pesquisa Agropecuária EMBRAPA. Sistema brasileiro de classificação de solos. 2. ed. Rio de Janeiro; 2006. 306 p.

Espírito-Santo FDB, Shimabukuro YE, Aragão LEOC, Machado ELM. Análise da composição florística e fitossociológica da floresta nacional do Tapajós com o apoio geográfico de imagens de satélites. Acta Amazonica 2005; 35(2): 155-173. http://dx.doi. org/10.1590/S0044-59672005000200006.

Ferreira LV, Sá RL, Buschbacher R, Batmanian G, Silva JMC, Arruda MB, et al. Identificação de áreas prioritárias para a conservação da biodiversidade através da representatividade das unidades de conservação e tipos de vegetação nas ecorregiões da Amazônia Brasileira. In: Instituto Socioambiental. Avaliação e identificação de ações prioritárias para a conservação, utilização sustentável e repartição dos benefícios da biodiversidade da amazônia brasileira. Macapá; 1999. Seminário de Consulta. Projeto Biodiversidade Amazônia [cited 2012 nov. 09]. Available from: http://www.socioambiental.org/inst/ sem/amazonia/macapa/index_html

Gonçalves IS, Dias HCT, Martins SV, Souza AL. Fatores edáficos e as variações florísticas de um trecho de Mata 
Ciliar do Rio Gualaxo do Norte, Mariana, MG. Revista Árvore 2011; 35(6): 1235-1243.

Güntzel AM, Dias NR, Coertjens CM, Silva GC, Vieira EA. Análise fitossociológica de um remanescente de vegetação na microbacia do Córrego Criminoso (Bacia do Rio Taquari, Coxim, MS, Brasil): subsídios para a recomposição da vegetação. Acta Botanica Brasilica 2011; 25(3): 586-592. http://dx.doi.org/10.1590/S010233062011000300011 .

Hammer Ø, Harper DAT, Ryan PD. 2001. PAST: Paleontological statistics software package for education and data analysis. Paleontologia Electronica 4(1): 1-9. [cited 2012 abr. 21]. Available from: http://palaeoelectronica.org/2001_1/past/issue1_01.htm

Hutcheson K. A test for comparing diversities based on the Shannon formula. Journal of Theoretical Biology 1970; 29(1): 151-154. http://dx.doi.org/10.1016/00225193(70)90124-4. PMid:5493290

Instituto Brasileiro de Geografia e Estatística - IBGE. Manual técnico da vegetação brasileira. Rio de Janeiro; 2012. 275 p.

Instituto Brasileiro de Geografia e Estatística - IBGE. Mapa de vegetação do Brasil. 1: 5.000 .000 Projeção Policônica. Rio de Janeiro; 1993.

Ivanauskas NM, Monteiro R, Rodrigues RR. Classificação fitogeográfica das florestas do Alto Rio Xingu. Acta Amazonica 2008; 38(3): 387-402. http:// dx.doi.org/10.1590/S0044-59672008000300003.

Ivanauskas NM, Monteiro R, Rodrigues RR. Composição florística de trechos florestais na borda sul-amazônica. Acta Amazonica 2004a; 34(3): 399-413. http://dx.doi.org/10.1590/S0044-59672004000300006.

Ivanauskas NM, Monteiro R, Rodrigues RR. Estrutura de um trecho de floresta amazônica na bacia do alto rio Xingu. Acta Amazonica 2004b; 34(2): 275-299. http:// dx.doi.org/10.1590/S0044-59672004000200015.

Köppen WP. Climatologia: com um estudio de los climas de la tierra. México: Fondo de Cultura Economica; 1948. 478 p.

Kunz SH, Ivanauskas NM, Martins SV, Silva E, Stefanello D. Análise da similaridade florística entre florestas do Alto Rio Xingu, da Bacia Amazônica e do Planalto Central. Revista Brasileira de Botânica 2009; 32(4): 725-736.

Kunz SH, Ivanauskas NM, Martins SV, Silva E, Stefanello D. Aspectos florísticos e fitossociológicos de um trecho de Floresta Estacional Perenifólia na Fazenda Trairão, Bacia do rio das Pacas, Querência-MT. Acta Amazonica 2008; 38(2): 245-254. http://dx.doi.org/10.1590/S004459672008000200007 .

Kunz SH, Ivanauskas NM, Martins SV, Stefanello D, Silva E. Fitossociologia do componente arbóreo de dois trechos de Floresta Estacional Perenifólia, Bacia do Rio das Pacas, Querência-MT. Ciência Florestal. 2012. In press.

Kunz SH, Martins SV, Ivanauskas NM, Silva E, Stefanello D. Estrutura Fitossociológica de um trecho de Floresta Estacional Perenifólia, Bacia do rio das Pacas, Querência - MT. Cerne 2010b; 16(2): 115-122. http://dx.doi.org/10.1590/S0104-77602010000200001.

Kunz SH, Martins SV, Ivanauskas NM, Stefanello D, Silva E. Fitossociologia de uma área de Floresta Estacional Perenifólia na Fazenda Amoreiras, Querência, MT. Revista Árvore 2010a; 34(4): 713-721. http://dx.doi. org/10.1590/S0100-67622010000400016.

Marchi TC, Jarenkow JA. Estrutura do componente arbóreo de mata ribeirinha no rio Camaquã, município de Cristal, Rio Grande do Sul, Brasil. Iheringia. Série Botânica 2008; 63(2): 241-248.

Martins SV, Colletti Júnior R, Rodrigues RR, Gandolfi $\mathrm{S}$. Colonization of gaps produced by death of bamboo clumps in a semideciduous mesophytic forest in southeastern Brazil. Plant Ecology 2004; 172(1): 121-131. http://dx.doi.org/10.1023/B:VEGE.0000026030.93687. c4.

Meira-Neto JAA, Martins FR. Composição florística de uma floresta estacional semidecidual montana no município de Viçosa-MG. Revista Árvore 2002; 26(4): 437-446. http://dx.doi.org/10.1590/S010067622002000400006 .

Missouri Botanical Garden - MOBOT. Tropicos Search. [cited 2008 Mar. 15]. Available from: http://mobot. mobot.org/W3T/Search/vast.html.

Moreno MR, Nascimento MT, Kurtz BC. Estrutura e composição florística do estrato arbóreo em duas zonas altitudinais na Mata Atlântica de encosta da região do Imbé, RJ. Acta Botanica Brasilica 2003; 17(3): 371-386. http://dx.doi.org/10.1590/S0102-33062003000300005.

Mueller-Dombois D, Ellenberg H. Aims and methods vegetation ecology. New York: John Wiley \& Sons; 1974.

Oliveira AN, Amaral IL, Nobre AD, Couto LB, Sado RM. Composition and floristic diversity in one hectare of a upland forest dense in Central Amazonia, Amazonas, Brazil. Biodiversity and Conservation 2003. In press.

Oliveira NA, Amaral IL. Aspectos florísticos, fitossociológicos e ecológicosde um sub-bosque de terra firme na Amazônia Central, Amazonas, Brasil. Acta Amazonica 2005; 35(1): 1-16. http://dx.doi. org/10.1590/S0044-59672005000100002.

Oliveira NA, Amaral IL. Florística e fitossociologia de uma floresta de vertente na Amazônia Central, Amazonas, Brasil. Acta Amazonica 2004; 34(1): 21-34. http://dx.doi.org/10.1590/S0044-59672004000100004.

Oliveira-Filho AT. Composição florística da e estrutura da comunidade da floresta de galeria do córrego da 
Paciência, Cuiabá, MT. Acta Botanica Brasilica 1989; 3(1): 91-112.

Pereira IM, Botelho AS, Machado ELM, Silveira CJA. Tree species occurring on ariparian slope and correlations with soil variables in the upper Grande River, Minas Gerais, Brazil. Ciência Rural 2012; 42(12): 2192-2198. http://dx.doi.org/10.1590/S010384782012005000092 .

Pielou EC. Ecological diversity. New York: John Wiley \& Sons; 1975.

Pinto JRR, Oliveira-Filho AT. Perfil florístico e estrutura da comunidade arbórea de uma floresta de vale no Parque Nacional da Chapada dos Guimarães, Mato Grosso, Brasil. Revista Brasileira de Botânica 1999; 22(1): 53-67.

Ribeiro JF, Walter BMT. As Matas de Galeria no contexto do bioma Cerrado. In: Ribeiro JF, Fonseca CEL, Souza-Silva JC, editores. Cerrado: caracterização e recuperação de Matas de Galeria. Planaltina: Embrapa Cerrados; 2001.

Rodrigues RR, Shepherd GJ. Fatores condicionantes da vegetação ciliar. In: Rodrigues EE, Leitão-Filho HF, editores. Matas ciliares: conservação e recuperação. São Paulo: EDUSP/FAPESP; 2000.

Romagnolo MB, Souza MC. Análise florística e estrutural de florestas ripárias do Alto Rio Paraná, Taquaruçu, MS. Acta botanica brasilica 2000; 14(2): 163-174.

Rossato DR, Toniato MTZ, Durigan G. Flora fanerogâmica não-arbórea do cerrado na Estação Ecológica de Assis, estado de São Paulo. Revista Brasileira de Botânica 2008; 31: 409-424.

Salis SM, Shepherd GJ, Joly CA. Floristic comparison of mesophytic semi deciduous forests of the interior of the state of São Paulo, Southeast Brazil. Vegetatio 1995; 119(2): 155-164. http://dx.doi.org/10.1007/ BF00045595.
Sampaio AB, Nunes RV, Walter BMT. Fitossociologia de uma Mata de Galeria na Fazenda Sucupira do CENARGEN, Brasília, DF. In: Leite LL, Saito CH, organizadores. Contribuição ao Conhecimento ecológico do Cerrado. Brasília: Universidade de Brasília; 1997.

Secretaria de Estado de Planejamento e Coordenação Geral - SEPLAN/MT. Dados secundários do DSEE/MT: Zoneamento-Divulga. [CD-ROM]; 1999. Versão 1.01.

Shepherd GJ. FITOPAC 2: manual do usuário. Campinas: UNICAMP; 2010.

Silva AF, Shepherd GJ. Comparações florísticas entre algumas matas brasileiras utilizando análise de agrupamento. Revista Brasileira de Botânica 1986; 9: 81-86.

Silva KE, Matos FDA, Ferreira MM. Composição florística e fitossociologia de espécies arbóreas do Parque Fenológico da Embrapa Amazônia Ocidental. Acta Amazonica 2008; 38(2): 213-222. http://dx.doi. org/10.1590/S0044-59672008000200004.

Sneath PHA, Sokal RR. Numerical taxonomy. San Francisco: W.H. Freeman; 1973.

Teixeira AP, Assis MA. Relação entre heterogeneidade ambiental e distribuição de espécies em uma floresta paludosa no Município de Cristais Paulista, SP, Brasil. Acta Botanica Brasilica 2009; 23(3): 843-853. http:// dx.doi.org/10.1590/S0102-33062009000300025.

Torres RB, Martins FR, Kinoshita LS. Climate, soil and tree flora relationships in forests inthe state of São Paulo, southeastern Brasil. Revista Brasileira de Botânica 1997; 20: 41-49.

Umetsu RK, Girard P, Matos MS, Silva CJ. Efeito da inundação lateral sobre a distribuição da vegetação ripária em um trecho do rio Cuiabá, MT. Revista Árvore 2011; 35(5): 1077-1087. http://dx.doi.org/10.1590/ S0100-67622011000600014.

Veloso HP, Rangel Filho ALR, Lima JCA. Classificação da vegetação brasileira, adaptada a um sistema universal. Rio de Janeiro: IBGE; 1991. 